\title{
The influences of morphine or ketamine pre-treatment on hemodynamic, acid-base status, biochemical markers of brain damage and early survival in rats after asphyxial cardiac arrest
}

\author{
Vladimir Kuklin ${ }^{1 * \dagger}$ (D), Nurlan Akhatov ${ }^{2,3+}$, Timofei Kondratiev ${ }^{4}$, Aidos Konkayev², Abai Baigenzhin ${ }^{3}$,
} Maiya Konkayeva ${ }^{2}$, Temirlan Karibekov ${ }^{3}$, Nicholas Barlow', Torkjel Tveita ${ }^{5}$ and Vegard Dahl1,6

\begin{abstract}
Background: In different models of hypoxia, blockade of opioid or N-methyl-D-aspartate (NMDA) receptors shows cardio- and neuroprotective effects with a consequent increase in animal survival. The aim of the study was to investigate effects of pre-treatment with Morphine or Ketamine on hemodynamic, acid-base status, early survival, and biochemical markers of brain damage in a rat model of asphyxial cardiac arrest (ACA).

Methods: Under anaesthesia with Thiopental Sodium $60 \mathrm{mg} / \mathrm{kg}$, i.p., Wistar rats $(n=42)$ were tracheostomized and catheters were inserted in a femoral vein and artery. After randomization, the rats were pre-treated with: Morphine $5 \mathrm{mg} / \mathrm{kg}$ i.v. $(n=14)$; Ketamine $40 \mathrm{mg} / \mathrm{kg}$ i.v. $(n=14)$; or equal volume of i.v. $\mathrm{NaCl} 0.9 \%$ as a Control $(n=14)$. ACA was induced by corking of the tracheal tube for $8 \mathrm{~min}$, and defined as a mean arterial pressure (MAP) $<20 \mathrm{mmHg}$. Resuscitation was started at 5 min after cardiac arrest (CA). Invasive MAP was recorded during experiments. Arterial $\mathrm{pH}$ and blood gases were sampled at baseline (BL) and 10 min after CA. At the end of experiments, all surviving rats were euthanised, brain and blood samples for measurement of Neuron Specific Enolase (NSE), s100 calcium binding protein B (s100B) and Caspase-3 (CS-3) were retrieved.

Results: At BL no differences between groups were found in hemodynamic or acid-base status. After 3 min of asphyxia, all animals had cardiac arrest (CA). Return of spontaneous circulation (MAP $>60 \mathrm{mmHg}$ ) was achieved in all animals within $3 \mathrm{~min}$ after CA. At the end of the experiment, the Ketamine pre-treated group had increased survival (13 of $14 ; 93 \%)$ compared to the Control $(7$ of $14 ; 50 \%)$ and Morphine (10 of $14 ; 72 \%)$ groups ( $p=0.035)$. Biochemical analysis of plasma concentration of NSE and S100B as well as an analysis of CS-3 levels in the brain tissue did not reveal any differences between the study groups.

Conclusion: In rats after ACA, pre-treatment with Morphine or Ketamine did not have any significant influence on hemodynamic and biochemical markers of brain damage. However, significantly better pH level and increased early survival were found in the Ketamine pre-treated group.
\end{abstract}

Keywords: Morphine, Ketamine, Rats, Asphyxial cardiac arrest, Early survival

\footnotetext{
* Correspondence: vkuklin@me.com

${ }^{\dagger}$ Vladimir Kuklin and Nurlan Akhatov contributed equally to this work.

'Department of Anaesthesiology and Intensive Care Medicine, Akershus

university hospital, Sykehusveien, 25, 1478 Lørenskog, Norway

Full list of author information is available at the end of the article
}

(c) The Author(s). 2019 Open Access This article is distributed under the terms of the Creative Commons Attribution 4.0 International License (http://creativecommons.org/licenses/by/4.0/), which permits unrestricted use, distribution, and

reproduction in any medium, provided you give appropriate credit to the original author(s) and the source, provide a link to the Creative Commons license, and indicate if changes were made. The Creative Commons Public Domain Dedication waiver (http://creativecommons.org/publicdomain/zero/1.0/) applies to the data made available in this article, unless otherwise stated. 


\section{Background}

Almost 35 years ago, Dr. Peter Safar wrote that "cerebral recovery from more than 5 min of cardiac arrest is hampered by complex secondary derangements of multiple organ systems after reperfusion" [1]. Actually, these 5 "golden" minutes determine the ability of cerebral neurones to regain ordinary function after anoxia. The ordinary function of cerebral neurones is conduction of electrical impulses across their length from the post-synaptic membrane of dendrites to the presynaptic membrane of an axon. The process is based on exchange of $\mathrm{Ca}^{2+}, \mathrm{Na}^{+}$and $\mathrm{K}^{+}$between the extra- and intracellular space of cerebral neurones, and therefore a lot of energy in the form of adenosine triphosphate (ATP) is needed to remove $\mathrm{Ca}^{2+}$ and $\mathrm{Na}^{+}$from the intracellular space of these cells. Cardiac arrest (CA) initiates a switch to anaerobic metabolism with very low production of ATP [2] and the increased [2] levels of lactate and $\mathrm{H}+$. Both acidosis and the lack of ATP inhibit the ions pumps, which are responsible for handling excessive intracellular accumulation of $\mathrm{Ca}^{2+}$ and $\mathrm{Na}^{+}$[2]. Moreover, preclinical studies demonstrate that acute hypoxia results in an uncontrolled release of glutamate with consequent stimulation of the N-methylD-aspartate (NMDA) receptors causing an excessive $\mathrm{Ca}^{2+}$ influx [3-8]. Meanwhile, the ATP reservoir in neurones can be completely depleted after 5 min of noflow state. In case of oxygen supplying restoration, two molecules of ATP are initially required to split glucose and restart the cellular respiration. Thus, the presence or absence of these two molecules of ATP in neurones actually determines restoring of both oxidative phosphorylation and the ordinary function of the neurones. Finally, prolonged intracellular $\mathrm{Ca}^{2+}$ overload results in increased mitochondrial permeability causing following release of cytochrome $\mathrm{C}$ from mitochondria, and consequent cleavage and activation of caspase-3 $[9,10]$. Caspase- 3 is an essential protease, which is involved in the early stage of apoptosis and it is generally accepted as a hallmark of irreversible cell death [10]. Recently, early elevated blood levels of two specific biochemical markers of neuronal damage, namely neuron-specific enolase (NSE) and S-100B protein, were also found to be associated with illness severity on hospital arrival, and with poor outcome after cardiac arrest [11]. Today, only therapeutic hypothermia has been shown to have a beneficial impact on the ion pump dysfunction, and thereby reduce neurotoxicity [12]. Interestingly, in hibernators, hypothermia is also believed to protect against hypoxic brain damage [13]. Meanwhile, if naloxone, a non-selective opioid receptor antagonist, is injected during the maintenance phase of hibernation, arousal is quickly achieved and the protective effects will vanish [13]. Delta opioid peptides, previously discovered to induce hibernation, have also been shown to protect rats from hypoxic brain damage [14]. Based on the ability of opioids to reduce the level of cyclic adenosine monophosphate (cAMP), and consequently to block $\mathrm{Na}^{+}$channels, it would be logic to propose that opioids might prevent the disturbance of ionic homeostasis during acute hypoxia. Indeed, preclinical studies demonstrate that pre-treatment with opioids can preserve cellular integrity after acute hypoxia in many organs and tissues including: intestine [15], skeletal muscle [16], myocardium [17, 18] and brain [19, 20]. Moreover, Morphine has been shown to significantly increase the early survival of mice and rats after acute hypoxia condition [21, 22]. Opioid receptor agonists also have demonstrated to cause increased tissue preservation and survival time of organs before their use in transplantation surgery [23]. In addition, high doses of opioids have been shown to inhibit NMDA receptors [24]. Other experimental studies have shown that inhibition of the NMDA receptor by Ketamine may reduce neuronal apoptosis and attenuate the systemic inflammatory response to tissue injury [25-27]. Moreover, the sympathomimetic effects of Ketamine might help to facilitate recovery of systemic blood pressure during cardiopulmonary resuscitation (CPR) [28]. All anaesthetics, with their ability to antagonise glutamatemediated excitotoxicity and inflammation might be the logic candidates for neuroprotective treatment during cardiac arrest. However, the additional ability of most anaesthetics to produce vasodilatation with a significant reduction of blood pressure can be the main argument against the idea to test their effects during CPR in humans. Theoretically, due to their minimal influences on hemodynamic status, Ketamine as well as Morphine might be considered as the safe candidates during neuroprotective treatment trials in CPR patients. However, we were not able to find any preclinical studies exploring the influence of Morphine or Ketamine application before or during CPR on arterial blood pressure blood gas tension, and early survival. Thus, the aim of this experimental study in a rat model of asphyxial cardiac arrest (ACA) was to investigate the influence of pre-treatment with Morphine or Ketamine on hemodynamics, acid-base status, brain damage markers, and early survival as endpoint of the study.

\section{Methods}

Ethics

The experimental study was approved by the Animal Care and Use Committee of the Astana Medical University, Astana, The Republic of Kazakhstan. The experimental procedures were performed according to the Guide for the Care and Use of Laboratory Animals, Eighth Edition, 2011 formulated by National Academy of Sciences, the United States of America. 


\section{Animal housing}

A total of 42 adult male Wistar rats, weighing $350-400 \mathrm{~g}$ were pushed from Astana Laboratory Animal Center, Astana, the Republic of Kazakhstan. All experiments were performed in the Experimental Animal Center, Astana Medical University, Astana, the Republic of Kazakhstan. The rats were housed in stainless steel cages (5 rats/cage) at conventional controlled conditions (temperature $25 \pm 2{ }^{\circ} \mathrm{C}$; relative humidity $50 \pm 10 \%$; $12 \mathrm{~h}$ light: dark cycle) and had a free access to standard laboratory food and tap water. The rats acclimated to the condition for 1 week prior to experiments and fasted overnight prior to surgery, with free access to water.

\section{Animal instrumentation}

Under anaesthesia with Thiopental Sodium (Kiev Medpeparat, Ukraine) $60 \mathrm{mg} / \mathrm{kg}$, i.p., rats were tracheostomized with a stainless-steel tracheal tube, connected to a small animal ventilator (TOPO Dual mode ventilator, Kent Scientific Corp, USA) and mechanically ventilated with a tidal volume of $8 \mathrm{ml} / \mathrm{kg}$ using room air. A 24G central venous catheter (Arrow) was inserted into the right femoral vein for drug administration and blood sampling. A $22 \mathrm{G}$ catheter (22G venflon, BD, Sweden) was inserted into the right femoral artery connected to pressure transducer for continuous blood pressure monitoring using Dash 5000, GE Healthcare, USA. Average time for the instrumentation was about $10 \mathrm{~min}$. At the end of the instrumentation the rats were given vecuronium bromide (Pfizer, USA) $2 \mathrm{mg} / \mathrm{kg}$, i.v.

\section{Animal randomization}

After instrumentation and following a $10 \mathrm{~min}$ pause, by means of sealed envelopes the rats were randomly assigned to 3 groups: 1$)$. Morphine group $(n=14)$, where the rats were given i.v. Morphine (Chimfarm Santo, Kazakhstan), $5 \mathrm{mg} / \mathrm{kg}, 10 \mathrm{~min}$ before inducing asphyxial cardiac arrest (ACA). 2). Ketamine group, $(n=14)$, where the rats were given i.v. Ketamine (Farmac, Ukraine) $40 \mathrm{mg} / \mathrm{kg} 10 \mathrm{~min}$ before ACA, 3). Control group $(n=14)$, where the rats were given an equal quantity of $\mathrm{NaCl} 0.9 \% 10$ min before ACA.

\section{Induction of ACA}

ACA was induced by corking of the tracheal tube for $8 \mathrm{~min}$ (Fig. 1), and defined as a mean arterial pressure $(\mathrm{MAP})<20 \mathrm{mmHg}$. Cardio-pulmonary resuscitation (CPR) was initiated by an i.v. injection of epinephrine $(0.02 \mathrm{mg} /$ $\mathrm{kg}$ ), followed by mechanical ventilation ( 80 breaths $/ \mathrm{min}$ ) using room air, and manual thoracic compressions (180 compressions/min). Restoration of spontaneous circulation (ROSC) was defined as a return of MAP $>60 \mathrm{mmHg}$. Ventilation was maintained until spontaneous breathing began. Core temperature (rectal) was kept between $36.5^{\circ} \mathrm{C}$ and $37.5^{\circ} \mathrm{C}$ using a heating pad. Arterial blood samples were taken at baseline, and $10 \mathrm{~min}$ after start of CPR. MAP was recorded at baseline, after i.v. injection of the study drugs or saline, at 1, 2, 3, 4, 5 min after induction of ACA and at 1, 5, $10,15,20 \mathrm{~min}$ in the post-resuscitation period. All surviving rats were euthanized with $180 \mathrm{mg} / \mathrm{kg}$ i.v. of Thiopental Sodium (Kiev Medpeparat, Ukraine) at the end of study.

\section{Measurement of biochemical markers}

Blood samples were centrifuged, plasma were aliquoted and snap frozen at $-70 \mathrm{C}$. Right after euthanasia brain was retrieved and brain tissue samples were snap frozen at $-70^{\circ} \mathrm{C}$. All samples were stored at $-70^{\circ} \mathrm{C}$ until analysis. Levels of neuron specific enolase (NSE), and s100 calcium binding protein B ( $100 \mathrm{~B})$ were measured in plasma samples which were collected at baseline and at $10 \mathrm{~min}$ in the post-resuscitation period $(n=7)$. Level of caspase-3 (CS-3) was measured in brain tissue samples from the surviving rats at the end of the experimental protocol, $20 \mathrm{~min}$ in the post-resuscitation period $(\mathrm{n}=7)$. CS-3 level was normalized to the protein concentration in the brain tissue samples and results presented as a

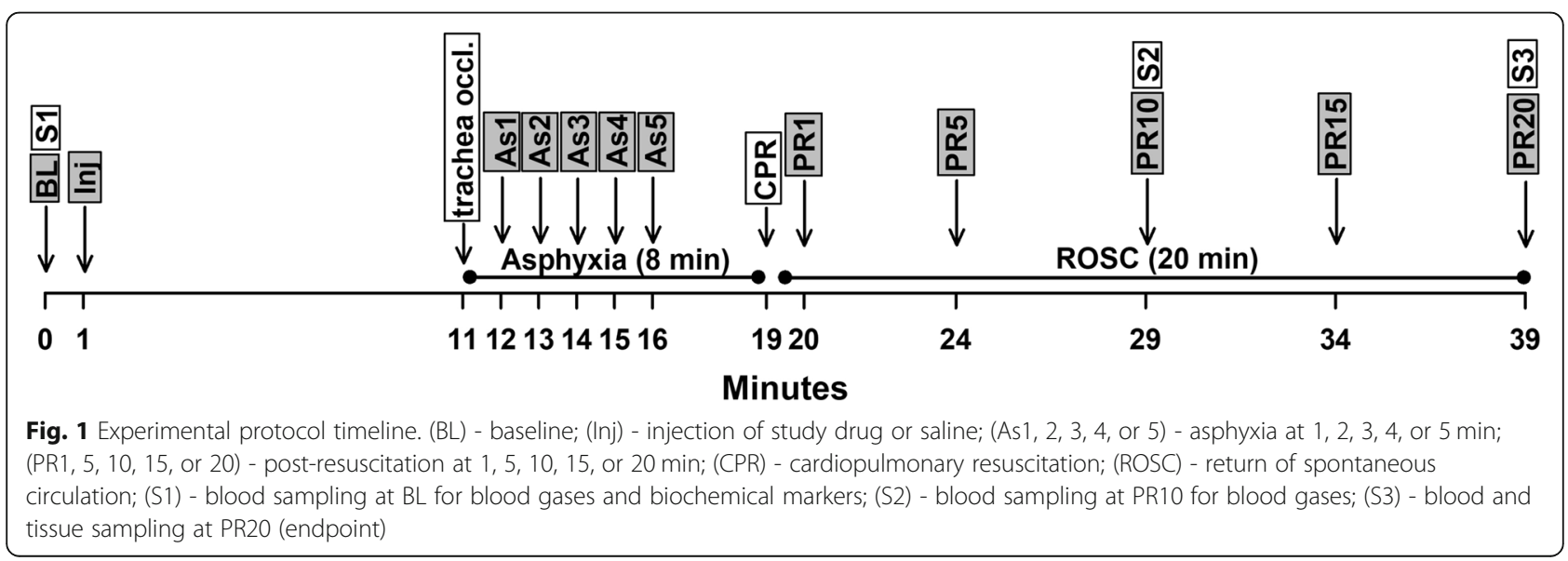


concentration per mg protein. All analysis were performed using Enzyme Linked Immunosorbent Assay (ELISA) kits provided by MyBioSource Inc. (San Diego, CA, USA). Protein content in the brain tissue samples was determined using Quick start Bradford protein assay from Bio-Rad (Hercules, CA, USA).

\section{Statistical analysis}

As we were not able to find any experimental study of Morphine or Ketamine application for animals with asphyxial cardiac arrest, for our study we calculated the sample size based on data from the research study of Endoh $\mathrm{H}$, et al. [22]. In the experimental study with rats exposed to hypoxic gas (5\% oxygen, $95 \% \mathrm{~N} 2$ ) for $70 \mathrm{~min}$, approximately $90 \%$ rats survived in the Morphine $(5 \mathrm{mg} /$ $\mathrm{kg}$ ) pre-treated group, and $40 \%$ survived in the control group. At $5 \%$ of significance level and $80 \%$ power, sample size will be pooled prevalence $=0.4+0.9 / 2=0.65$.

Sample Size $=2(1.96+0.842)^{2} \times 0.65(1-0.65) /(-0.5)^{2}=$ 14.26.

based on formula of sample size $=2(Z \alpha / 2+Z \beta)^{2} \times P$ $(1-\mathrm{P}) /(\mathrm{p} 1-\mathrm{p} 2)^{2}$.

where $\mathrm{Z} \alpha / 2=\mathrm{Z} 0.05 / 2=\mathrm{Z} 0.025=1.96$ (From $\mathrm{Z}$ table) at type 1 error of $5 \%$ and.

$\mathrm{Z} \beta=\mathrm{Z} 0.20=0.842$ (From $\mathrm{Z}$ table) at $80 \%$ power.

$\mathrm{p} 1-\mathrm{p} 2=$ Difference in proportion of events in two groups $\mathrm{P}=$ Pooled prevalence $=($ prevalence in case group [p1] + prevalence in the control group [p2])/2.

Data were analyzed and presented using SigmaPlot statistical software version 13.0 (Systat Software Inc., San Jose, CA, USA). Data were tested for normal distribution with Shapiro-Wilks test. Differences in values between groups were analyzed using one-way ANOVA on ranks. If significant differences were found, all pairwise multiple comparison procedures using Dunn's method was applied to compare values between groups. Blood gas data and data of biochemical markers made after 10 min in the post-resuscitation period vs. corresponding baseline levels within each group were compared using a paired $t$-test. Survival was tested using log-rank KaplanMeier test. When significant differences were found, all pairwise multiple comparison procedures were tested using Holm-Sidak method to compare differences between groups. Differences were considered significant at $p<0.05$.

\section{Results}

At baseline (BL), no significant differences in MAP, blood gases, or acid-base status were found between groups (Figs. 2-3, Table 1). As depicted in Fig. 2, pre-treatment of rats with Ketamine resulted in a significant reduction in MAP when compared to rats pre-treated with Morphine or saline. During the first 3 min of asphyxia MAP consistently decreased in all groups resulting in ACA which eventually took place in all animals when invasive MAP dropped below $20 \mathrm{mmHg}$ and remained around zero following $5 \mathrm{~min}$ of asphyxia (Fig. 2). Within $3 \mathrm{~min}$, after start of CPR the rats in all groups had ROSC (no differences between the groups) with regained an invasive MAP $>100 \mathrm{mmHg}$ (Fig. 2). At 15 min in post-resuscitation period rats in the Ketamine group had MAP at a significantly higher level compared to rats in the Morphine group, however at the $20 \mathrm{~min}$ postresuscitation no significant difference in MAP between groups was observed. All groups had significantly increased plasma lactate level $(10.5-13 \mathrm{mmol} / \mathrm{l})$ compared to their baseline levels (1.8-3 mmol/l) (Fig. 3:A). No significant

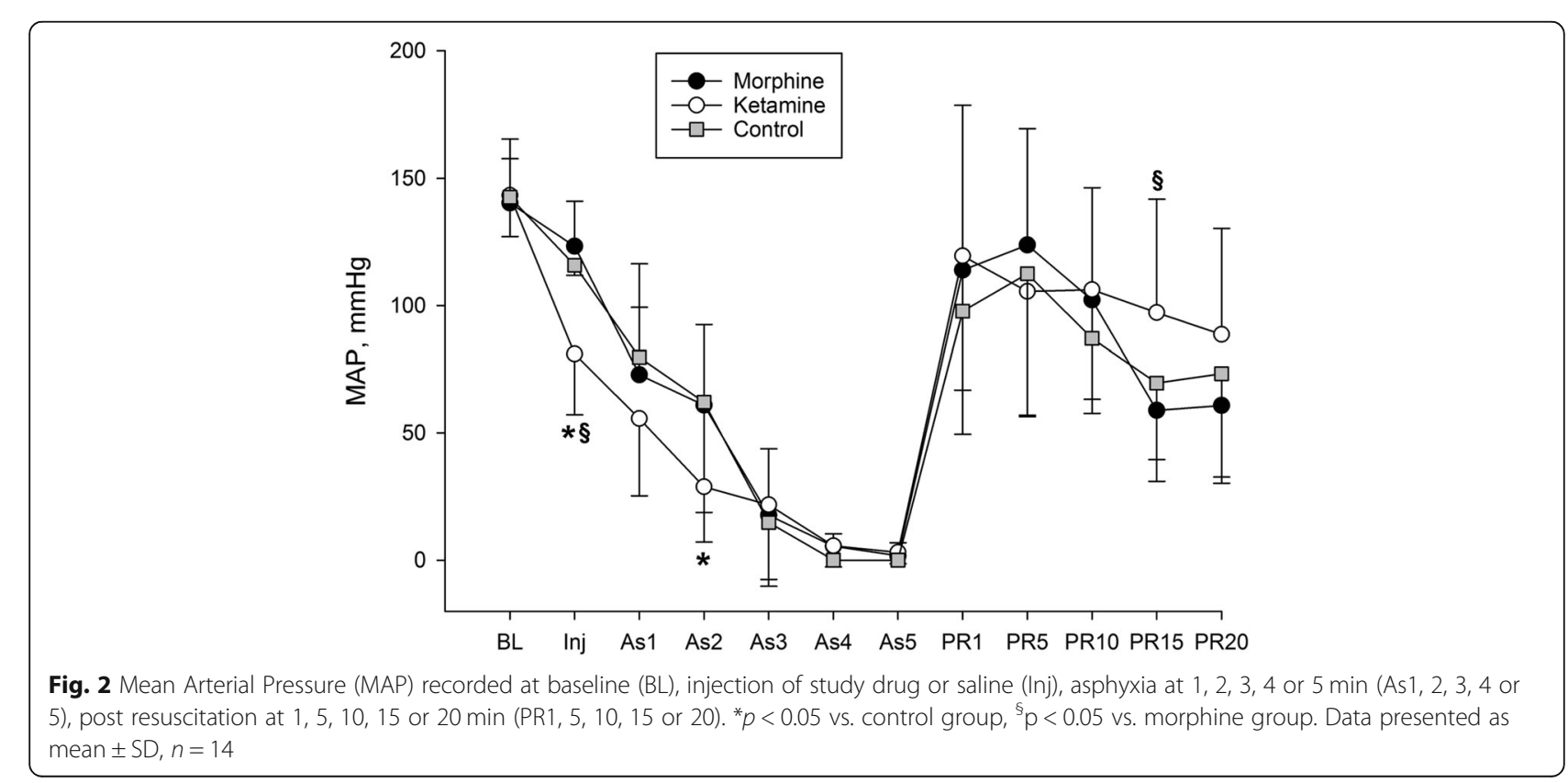



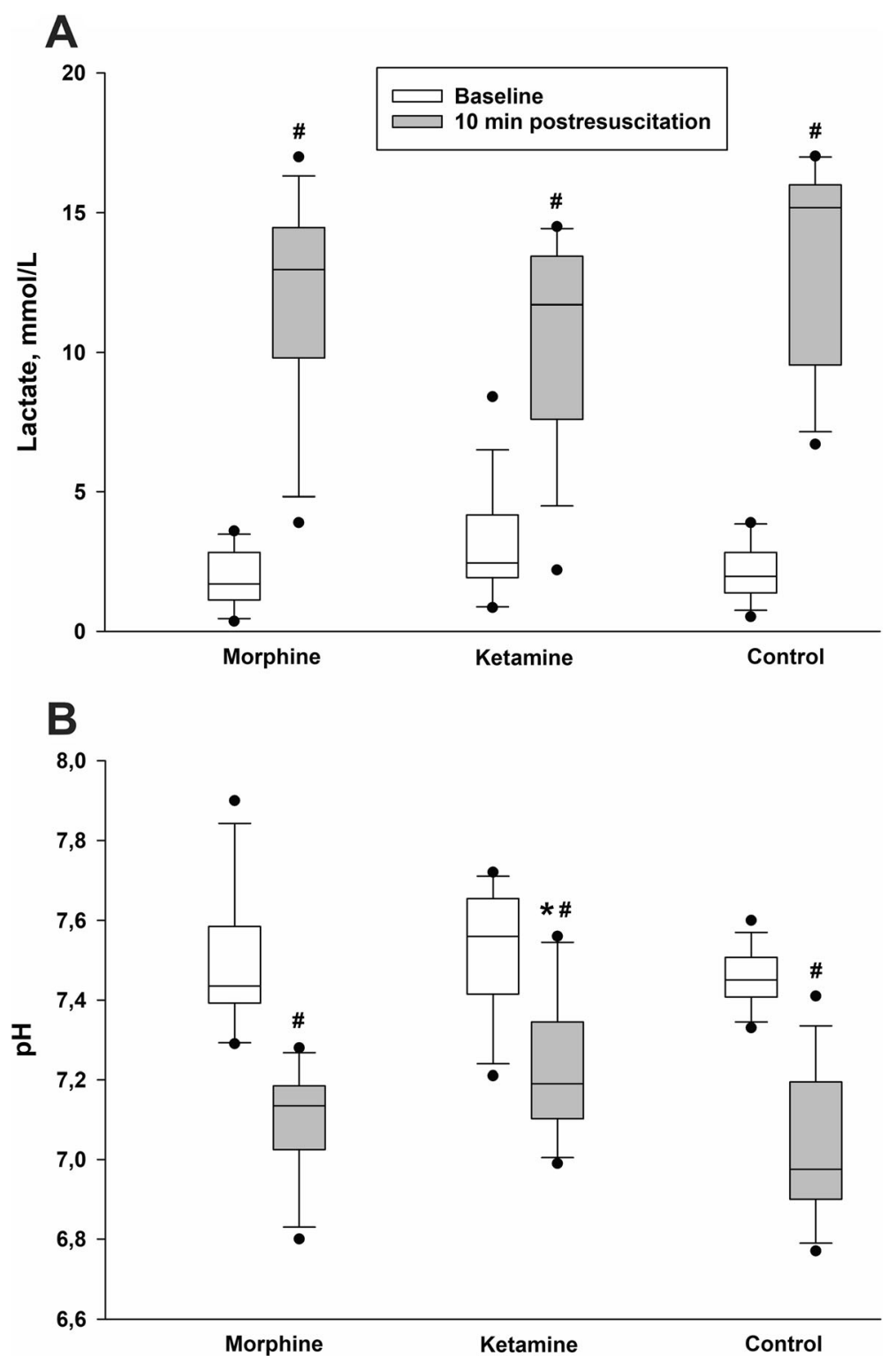

Fig. 3 Serum lactate level (a) and accumulation of $\mathrm{H}^{+}$in the blood (b) measured at baseline and at 10 min in post resuscitation period. Data presented as median 25th and 75th percentiles (vertical boxes with a median line), 10th and 90th percentiles (error bars) and 5th and 95th percentiles (black dots) where \# $p<0.05$ vs. baseline levels and * $p<0.05$ vs. control group

Table 1 Blood gases ( $\mathrm{mm} \mathrm{Hg}$ ) and acid base variables measured at the baseline (BL) and at 10 min after asphyxia in postresuscitation period (10 PR), p between the groups. Data presented as mean \pm SD

\begin{tabular}{|c|c|c|c|c|c|c|c|}
\hline & \multicolumn{2}{|l|}{ morphine } & \multicolumn{2}{|l|}{ ketamine } & \multicolumn{2}{|l|}{ control } & \multirow[t]{2}{*}{$p$} \\
\hline & $\mathrm{BL}$ & $10 P R$ & $\mathrm{BL}$ & $10 P R$ & $\mathrm{BL}$ & $10 P R$ & \\
\hline $\mathrm{SaO}_{2}$ & $94.1 \pm 5.2$ & $66.7 \pm 27.3$ & $93.7 \pm 7.4$ & $74.1 \pm 21.1$ & $93.4 \pm 4.3$ & $68.3 \pm 23.5$ & ns \\
\hline $\mathrm{PaO}_{2}$ & $90.8 \pm 16.5$ & $63 \pm 21.7$ & $105 \pm 18.9$ & $70.8 \pm 33.8$ & $88.7 \pm 18.5$ & $64.9 \pm 25.8$ & ns \\
\hline $\mathrm{PaCO}_{2}$ & $30.4 \pm 12.3$ & $39.1 \pm 26.9$ & $28.3 \pm 13.6$ & $22.6 \pm 12.3$ & $34.3 \pm 12.7$ & $36.2 \pm 22.6$ & ns \\
\hline $\mathrm{HCO}_{3}$ & $24.4 \pm 4.6$ & $10 \pm 3.1$ & $24.3 \pm 5.1$ & $10.4 \pm 3.4$ & $24.4 \pm 4.2$ & $10.3 \pm 3.7$ & ns \\
\hline $\mathrm{BE}$ & $6 \pm 1.7$ & $-19.8 \pm 2.3$ & $6.8 \pm 2.2$ & $-18.6 \pm 4.5$ & $5.2 \pm 2.8$ & $-19.9 \pm 4.4$ & ns \\
\hline
\end{tabular}


difference in plasma lactate level between groups was observed. All groups had significantly lower $\mathrm{pH}$ value $10 \mathrm{~min}$ post-resuscitation (7.0-7.2) compared to intragroup baseline (7.4-7.5) (Fig. 3:B). In addition, rats in the Ketamine group had significantly lower accumulation of hydrogen ions in blood as compared to rats in the Control group (Fig. 3:B). All rats in the study were ventilated with room air only during the whole experiment. Only one rat in the Ketamine treated group died during the post-resuscitation period (death occurred between 10 and 20 min after ROSC). In contrast to the Ketamine group, significantly higher mortality $(p=0.035)$ was observed in the Control group (Fig. 4), where 7 of 14 rats had not survived 20 min after ROSC, 3 of them had died during the first $10 \mathrm{~min}$ of the postresuscitation period. In the Morphine treated group, totally 4 of 14 rats died within 20 min of the post-resuscitation period, 2 of them had died during the first $10 \mathrm{~min}$ after ROSC. No differences in blood gases variables (such as $\left.\mathrm{SaO}_{2}, \mathrm{PaO}_{2}, \mathrm{PaCO}_{2}\right)$ and acid-base status variables $\left(\mathrm{HCO}_{3}\right.$ and $\mathrm{BE}$ ) were observed between groups. All above mentioned variables except for $\mathrm{PaCO}_{2}$ were significantly decreased compared to intragroup baseline (Table 1). Biochemical analysis of plasma concentration of NSE (Table 2) and s100 calcium binding protein B (data not shown) as well as an analysis of caspase-3 levels in the brain tissue (Table 2) did not reveal any differences between the study groups. NSE level was significantly increased after $20 \mathrm{~min}$ of postresuscitation period compared to baseline in all three groups (Table 2).

\section{Discussion}

The main finding of the present study was that pretreatment of rats with Ketamine significantly increased early survival after $8 \mathrm{~min}$ of asphyxia and followed by 5 min cardiac arrest. Pre-treatment of rats with Morphine or Ketamine did not result in any significant changes of hemodynamic and biochemical markers of brain damage. However, in the Ketamine pre-treated group rats had significantly better $\mathrm{pH}$ levels as compared to the Control group.

The rat model of ACA used in our study was developed by Katz L and co-authors in 1995 [29]. In their study, the authors presented the reproducible and welldocumented outcome model of asphyxial cardiac arrest in rats [29]. In this model, rats were anaesthetized with $3 \%$ Halothane and 60:40\% Nitrous Oxide $\left(\mathrm{N}_{2} \mathrm{O}\right)$ :oxygen $\left(\mathrm{O}_{2}\right)$ and paralyzed with Vecuronium $2 \mathrm{mg} / \mathrm{kg}$ i. v. Followed apneic asphyxia for $8 \mathrm{~min}$ led to the well reproducible cessation of blood circulation at 3-4 min of apnea and cardiac arrest for 4-5 min. Survival to $72 \mathrm{~h}$ after ACA was achieved in 9 of 10 rats $(90 \%)$ in the study. All survived rats had mild neurologic deficit scores that primarily were due to hind-leg spastic paralysis. However, the paralysis was due to insertion of arterial and venous catheter in the femoral vessels with following ligation and cessation of blood circulation in the leg [29]. In contrast to the «classical» model, in our study the rats were anesthetized with Thiopental. Recently it was demonstrated that Thiopental significantly depresses both cardiac and respiratory function, making cardiac pulmonary resuscitation in rats more difficult [28]. Definitely, application of Thiopental anaesthesia and absence of pre- and post-100\% oxygenation in our study resulted in $50 \%$ mortality in the Control group (Fig. 4). The high mortality in our study makes our experimental model more relevant to clinical situations

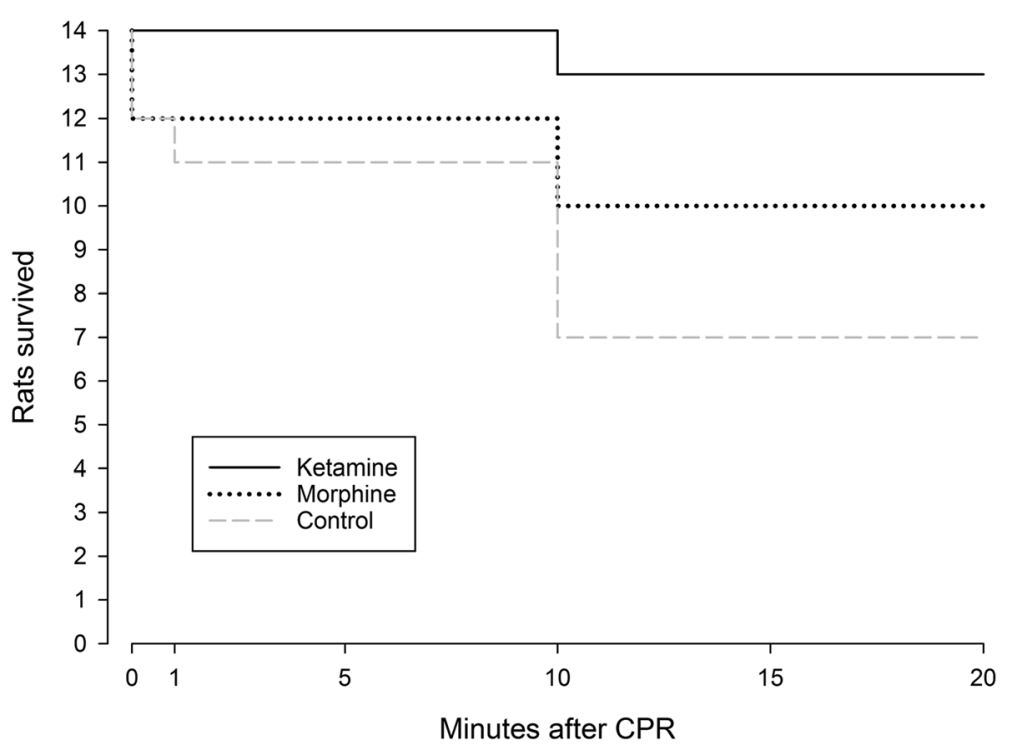

Fig. 4 Cumulative survival of the rats at 20 min after CPR, $p=0.035$ in ketamine vs. control group, $n=14$ 
Table 2 Biochemical analysis of neuron specific enolase (NSE) plasma concentration in ng/ml and caspase-3 (CS-3) levels in the brain tissue of the rats in $\mathrm{ng} / \mathrm{ml} / \mathrm{mg}$ protein, measured at the baseline (BL) and at $20 \mathrm{~min}$ after asphyxia in post-resuscitation period (20 PR), p between the groups. Data presented as mean \pm SD

\begin{tabular}{|c|c|c|c|c|c|c|c|}
\hline & \multicolumn{2}{|c|}{ morphine } & \multicolumn{2}{|c|}{ ketamine } & \multicolumn{2}{|l|}{ control } & \multirow[t]{2}{*}{$p$} \\
\hline & $\mathrm{BL}$ & $20 P R$ & $\mathrm{BL}$ & $20 P R$ & $\mathrm{BL}$ & $20 P R$ & \\
\hline NSE & $1.2 \pm 0.1$ & $1.8 \pm 0.5$ & $0.9 \pm 0.1$ & $3.5 \pm 2.2$ & $1.1 \pm 0.2$ & $2.4 \pm 0.5$ & ns \\
\hline CS-3 & - & $0.14 \pm 0.02$ & - & $0.16 \pm 0.06$ & - & $0.17 \pm 0.05$ & ns \\
\hline
\end{tabular}

where early survival after in-hospital cardiac arrest recently was demonstrated approximately to be $50 \%$ for all patients with well-documented cardiac rhythms [30]. Despite on basic anaesthesia with Thiopental, pretreatment with Ketamine dramatically increased early survival (93\%) in the rats (Fig. 5). The results are supported by an earlier finding of Reid $\mathrm{KH}$ et al. [28], who demonstrated a successful restoration of cardiac function after CA in $81 \%$ of rats anesthetized with Ketamine versus ROSC in 39\% rats under Thiopental anaesthesia. In our opinion, high early survival (90\%) in the «classical» model of Katz L and co-authors [29] might also be related to NMDA blockade by $\mathrm{N}_{2} \mathrm{O}$. Meanwhile, two experimental studies testing effects of two NMDA antagonist, MK-801 and GPI-3000 demonstrated no improvement of survival rate and brain outcome after CA in a dog model [31, 32]. These studies did not suggest any mechanisms for the negative results, but they apparently have contributed to a lack of interest for testing NMDA blockade in CA for years. However, new published experimental data demonstrates that pretreatment of zebrafish with Ketamine protects against cardiac arrest-induced brain injury by inhibiting $\mathrm{Ca}^{2+}$ wave propagation, which consequently improves survival rate [33]. More recently, a study of the effects of using the noncompetitive NMDA antagonist Ifenprodil demonstrated a significant reduction of brain edema following CA in rats [34]. In this study, i.v. injection of Ifenprodil caused a significant reduction of MAP before $\mathrm{CA}$ and much more stable hemodynamic after CA as compared with saline treated animals [34]. Consistent with these findings [34], in our study the rats pretreated with Ketamine demonstrated a significant reduction of MAP right after i.v. injection, but showed a relatively stable hemodynamic after CA. Summarising the above, most likely that the sympathomimetic effects of Ketamine together with subsequent improvement in $\mathrm{pH}$ levels of rats are the main cause for the significant increment of early survival in our study. As it is not possible to apply cardiac arrest to animal without any anaesthesia (main limitation of all experimental models of cardiac arrest), the sympathomimetic effects and possible neuroprotective features of Ketamine [35] should be tested in patients with cardiac arrest. Additional topic for possible clinical research of
Ketamine as well as Morphine could be their analgesic effects as vigorous thoracic compression with possible trauma of the ribs may lead to severe pain and stress reactions in patients surviving CPR.

In an experimental model with rats exposed to hypoxic gas $\left(5 \% \mathrm{O}_{2}, 95 \% \mathrm{~N}_{2}\right)$ for $70 \mathrm{~min}$, all seven rats in the Naloxone pre-treated group died at the end of the experiments while only one out of seven rats died in the Morphine (5 $\mathrm{mg} / \mathrm{kg}$ ) pre-treated group, and five of seven rats died in the control group [22]. The results were very similar to previously published finding obtained from mice in the same model [21]. Interestingly, pre-treatment with Morphine in these studies significantly attenuated MAP and enhanced hypoxic ventilatory depression but, nevertheless, improved hypoxic survival $[21,22]$. In our experiments where the rats were exposed to $8 \mathrm{~min}$ anoxia, pretreatment with Morphine resulted in non-significant attenuation of MAP (Fig. 2) and non-significant positive trend in survival (Fig. 4). We were not able to find any publications looking at pre-treatment with Morphine and survival rate in animals after cardiac arrest. However, two recent retrospective studies demonstrated that patients who were treated with opioids before or during CA had a statistically significantly higher survival rate [36] and much better neurological outcome [37] compared to untreated patients.

The rationale for analyzing plasma levels of S-100B protein and NSE in this study was their different distribution within the white (S100B protein) and grey (NSE) matter of the brain, and the fact that both of them are extensively involved in the pathogenesis of anoxial brain damage [38]. S100 B protein is an intracellular calciumbinding dimer that has a molecular weight of $21 \mathrm{kDa}$ and a half-life of two hours. Thanks to the low molecular weight, S100 B easily crosses the blood-brain barrier and ends up rapidly in the systemic circulation. In this study, we did not find any changes in the plasma level of S100 B, and therefore data is not presented. NSE is a neuronal isoform of the glycolytic enzyme enolase that has a molecular weight of $78 \mathrm{kDa}$ and a twenty-four hours half-life. Further, NSE is extensively involved in glucose metabolism in the neurons and can be detected only in neuronal and neuroendocrine tissues. Due to this organ specificity, concentration of NSE in blood is often elevated because of relative rapid and massive neuronal 
destruction. In the present study, plasma levels of NSE were found to be slightly increased at $20 \mathrm{~min}$ after cardiac arrest in all groups compared to the baseline measurement (Table 2), but the levels did not exceed the normal range of NSE in blood, considered to be $\leq 15 \mathrm{ng} /$ $\mathrm{ml}$. Caspase-3 is involved in the early stage of apoptosis and is currently considered to be the hallmark of irreversible cell death [10]. As depicted in Table 2, tissue levels of caspase- 3 remained low in all study groups and no significant differences between groups were found. When summarising all the biochemical findings in the study, we can conclude that independent of pretreatment, there was an absence of biochemical signs of apoptosis in the rats at $20 \mathrm{~min}$ after ACA. Our results find support in a previous study [39] of post-mortem adult rat brains, which demonstrated absence of autolytic damages in the ultrastructure of cerebral neurons during the first $6 \mathrm{~h}$ after warm asphyxial cardiac arrest. Interestingly, in the referred study, the activation of caspase-3 was observed in a significant number of neurons of the cerebellum and neocortex only after $9 \mathrm{~h}$ following asphyxial cardiac arrest [39].

Our study has certain limitations. We did not perform any monitoring of cardiac output in the rats and therefore no cardio depressive effect of Morphine or Ketamine after ACA was elucidated. However, as arterial blood pressure and accumulation of lactate were not significantly different between the groups we may speculate whether the negative influence of Morphine or Ketamine on heart function were clinically irrelevant. We did not measure brain oxygen demand in our rats, and therefore the influence of Morphine or Ketamine on oxygen consumption remains unsettled. Finally, rapid intracellular accumulation of both $\mathrm{Na}^{+}$and $\mathrm{Ca}^{2+}$ during anoxia might have contributed to development of brain edema, thus further research is warranted to elucidate the influence of Morphine or Ketamine on the development of cerebral edema after CA.

\section{Conclusions}

Pre-treatment with Ketamine before ACA significantly improved early survival and attenuated alterations in $\mathrm{pH}$ after ROSC when compared to placebo control rats. Additionally, a positive trend for increased survival was also observed in the rats pre-treated with Morphine. Further experimental studies are needed to elucidate effects of Ketamine and/or Morphine on long-term survival and neurological outcome after ACA.

\section{Abbreviations}

ACA: asphyxial cardiac arrest; BL: baseline; CA: cardiac arrest; CPR: Cardiopulmonary resuscitation; CS-3: Caspase-3; ELISA: Enzyme Linked Immunosorbent Assay; MAP: mean arterial pressure; NMDA: N-methyl-Daspartate; NSE: neuron specific enolase; ROSC: Return of spontaneous circulation; s100B: s100 calcium binding protein B

\section{Acknowledgements}

We would like to thank Prof. Yermek Abibullayevich Akhmetov, Vice-rector for scientific and clinical works for the personal help with organization of the study in the Experimental Animal Center, Astana Medical University, Astana, The Republic of Kazakhstan.

\section{Authors' contributions}

VK, NA, TK, AK, AB and TK mainly designed the study. VK, NA, TK, and MK took part in the experimental part of the study. TK performed measurement of biochemical markers of brain damage. VK, NA and TK performed data analysis. TK prepared all Figs. VK, NA, TK, NB, TT and VD were the major contributors in writing the manuscript. All authors read and accepted the final manuscript.

\section{Funding}

The present study was supported, in part, by the intern funds from the departments of Anaesthesiology and Intensive Care of Akershus university hospital, Lørenskog, Norway, National Scientific Medical Center, Astana, The Republic of Kazakhstan, and Astana Medical University, Astana, The Republic of Kazakhstan. Vladimir Kuklin has received the travel grant from Norwegian Society of Anaesthesiology, and travel stipend from Helse Sør-Øst RHF. The funding bodies did not have any influence on the design of the study, collection, analysis and interpretation of data and writing the manuscript.

\section{Availability of data and materials}

The data that support the findings of this study in form of Excel files are available from the corresponding author.

\section{Ethics approval and consent to participate}

The experimental study was approved by the Animal Care and Use Committee of the Astana Medical University, Astana, Kazakhstan. The experimental procedures were performed according to the Guide for the Care and Use of Laboratory Animals, Eighth Edition, 2011 formulated by National Academy of Sciences, the United States of America.

Consent for publication

Not applicable.

\section{Competing interests}

The authors declare that they have no competing interests.

\section{Author details}

${ }^{1}$ Department of Anaesthesiology and Intensive Care Medicine, Akershus university hospital, Sykehusveien, 25, 1478 Lørenskog, Norway. ${ }^{2}$ Department of Anaesthesiology and Intensive Care Medicine, Astana Medical University, Nur-Sultan, Kazakhstan. ${ }^{3}$ Department of Anaesthesiology and Intensive Care Medicine, National Scientific Medical Center, Nur-Sultan, Kazakhstan. ${ }^{4}$ Anaesthesia and Critical Care Research Group, Department of Clinical Medicine, UiT - The Arctic University of Norway, 9037 Tromsø, Norway. ${ }^{5}$ Division of Surgical Medicine and Intensive Care, University Hospital of Northern Norway, 9038 Tromsø, Norway. ${ }^{6}$ Department of Anaesthesiology and Intensive Care Medicine, University of Oslo, Oslo, Norway.

Received: 5 February 2019 Accepted: 31 October 2019

Published online: 20 November 2019

\section{References}

1. Safar P. Cerebral resuscitation after cardiac arrest: a review. Circulation. 1986; 74(6 Pt 2):IV138-53.

2. Siesjo BK, Bengtsson F, Grampp W, Theander S. Calcium, excitotoxins, and neuronal death in the brain. Ann N Y Acad Sci. 1989;568:234-51.

3. Schmitt KR, Tong G, Berger F. Mechanisms of hypothermia-induced cell protection in the brain. Molecular and Cellular Pediatrics. 2014;1:7. https:// doi.org/10.1186/s40348-014-0007-x

4. Robinson MB, Coyle JT. Glutamate and related acidic excitatory neurotransmitters: from basic science to clinical application. FASEB J. 1987;1:446-55.

5. Fonnum F. Glutamate: A neurotransmitter in mammalian brain. J Neurochem. 1984:42:1-11.

6. Choi DW. Glutamate neurotoxicity and diseases of the nervous system. Neuron. 1988;1:623-34. 
7. Nicholls D, Attwell D. The release and uptake of excitatory amino acids. Trends Pharmacol Sci. 1990;11:462-8.

8. Bondy SC, LeBel CP. The relationship between excitotoxicity and oxidative stress in the central nervous system. Free Radic Biol Med. 1993;14:633-42.

9. Bernardi P, Rasola A. Calcium and cell death: the mitochondrial connection. Subcell Biochem. 2007:45:481-506.

10. Earnshaw WC, Martins LM, Kaufmann SH. Mammalian caspases: structure, activation, substrates, and functions during apoptosis. Annu Rev Biochem. 1999;68:383-424.

11. Calderon LM, Guyette FX, Doshi AA, Callaway CW, Rittenberger JC. Combining NSE and S100B with clinical examination findings to predict survival after resuscitation from cardiac arrest. Resuscitation. 2014;85(8): 1025-9. https://doi.org/10.1016/j.resuscitation.2014.04.020 Epub 2014 Apr 30.

12. Phillips KF, Deshpande LS, DeLorenzo RJ. Hypothermia reduces calcium entry via the $\mathrm{N}$-methyl-D-aspartate and ryanodine receptors in cultured hippocampal neurons. Eur J Pharmacol. 2013;698(1-3):186-92. https:// doi.org/10.1016/j.ejphar.2012.10.010 Epub 2012 Oct 17.

13. Tamura $Y$, Shintani M, Inoue H, Monden M, Shiomi H. Regulatory mechanism of body temperature in the central nervous system during the maintenance phase of hibernation in Syrian hamsters: involvement of $\beta$ endorphin. Brain Res. 2012;1448:63-70. https://doi.org/10.1016/j.brainres. 2012.02.004 Epub 2012 Feb 9.

14. Borlongan CV, Hayashi T, Oeltgen PR, Su TP, Wang Y. Hibernation-like state induced by an opioid peptide protects against experimental stroke. BMC Biol. 2009;7:31. https://doi.org/10.1186/1741-7007-7-31.

15. $Y$, Wu YX, Hao YB, Dun Y, Yang SP. Role of endogenous opioid peptides in protection of ischemic preconditioning in rat small intestine. Life Sci. 2001; 68:1013-9.

16. Addison PD, Neligan PC, Ashrafpour H, Khan A, Zhong A, Moses M, et al. Noninvasive remote ischemic preconditioning for global protection of skeletal muscle against infarction. Am J Physiol Heart Circ Physiol. 2003;285:H1435-43.

17. Romano MA, Seymour EM, Berry JA, McNish RA, Bolling SF. Relative contribution of endogenous opioids to myocardial ischemic tolerance. J Surg Res. 2004;118:32-7.

18. Peart JN, Gross GJ. Exogenous activation of delta-and kappa-opioid receptors affords cardioprotection in isolated murine heart. Basic Res Cardiol. 2004;99:29-37.

19. Zhang J, Haddad GG, Xia Y. Delta-, but not mu-and kappa-, opioid receptor activation protects neocortical neurons from glutamate-induced excitotoxic injury. Brain Res. 2000;885:143-53.

20. Zhang J, Gibney GT, Zhao P, Xia Y. Neuroprotective role of delta-opioid receptors in cortical neurons. Am J Physiol Cell Physiol. 2002;282:C1225-34.

21. Endoh H, Taga K, Yamakura T, Sato K, Watanabe I, Fukuda S, et al. Effects of naloxone and morphine on acute hypoxic survival in mice. Crit Care Med. 1999;27:1929-33.

22. Endoh $\mathrm{H}$, Honda T, Ohashi S, Shimoji K. Naloxone improves arterial blood pressure and hypoxic ventilatory depression, but not survival, of rats during acute hypoxia. Crit Care Med. 2001;29:623-7.

23. Chien S, Oeltgen PR, Diana JN, Salley RK, Su TP. Extension of tissue survival time in multiorgan block preparation with a delta opioid DADLE (D-Ala2, DLeu5-enkephalin). J Thorac Cardiovasc Surg. 1994;107:964-7.

24. Yamakura T, Sakimura K, Shimoji K. Direct inhibition of the N-methyl-Daspartate receptor channel by high concentrations of opioids. Anesthesiology. 1999;91:1053-63.

25. Orser BA, Pennefather PS, MacDonald JF. Multiple mechanisms of ketamine blockade of $\mathrm{N}$-methyl-D-aspartate receptors. Anesthesiology. 1997:86:903-17.

26. Himmelseher S, Pfenninger E, Georgieff M. The effects of ketamine- isomers on neuronal injury and regeneration in rat hippocampal neurons. Anesth Analg. 1996;83:505-12.

27. Himmelseher S, Pfenninger E, Kochs E, Auchter M. S()-ketamine upregulates neuronal regeneration associated proteins following glutamate injury in cultured rat hippocampal neurons. J Neurosurg Anesthesiol. 2000;12:84-94.

28. Reid KH, Paskitti M, Guo SZ, Schmelzer T, Iyer V. Experience with ketamine and sodium pentobarbital as anesthetics in a rat model of cardiac arrest and resuscitation. Resuscitation. 2003:57:201-10.

29. Katz L, Ebmeyer U, Safar P, Radovsky A, Neumar R. Outcome model of asphyxial cardiac arrest in rats. J Cereb Blood Flow Metab. 1995;15(6):1032-9.
30. Meaney PA, Nadkarni VM, Kern KB, Indik JH, Halperin HR, Berg RA. Rhythms and outcomes of adult in-hospital cardiac arrest. Crit Care Med. 2010;38:101-8.

31. Sterz F, Leonov Y, Safar P, Radovsky A, Stezoski SW, Reich H, et al. Effect of excitatory amino acid receptor blocker MK-801 on overall, neurologic, and morphologic outcome after prolonged cardiac arrest in dogs. Anesthesiology. 1989;71(6):907-18.

32. Helfaer MA, Ichord RN, Martin L, Hurn PD, Castro A, Traystman RJ. Treatment with the competitive NMDA antagonist GPI 3000 does not improve outcome after cardiac arrest in dogs. Stroke. 1998;29(4):824-9.

33. Xu DJ, Wang B, Zhao X, Zheng Y, Du JL, Wang YW. General anesthetics protects against cardiac arrest-induced brain injury by inhibiting calcium wave propagation in zebrafish. Mol Brain. 2017;10(1):44. https://doi.org/10. 1186/s13041-017-0323-X.

34. Xiao F, Pardue S, Arnold T, Carden D, Alexander JS, Monroe J, et al. Effect of ifenprodil, a polyamine site NMDA receptor antagonist, on brain edema formation following asphyxial cardiac arrest in rats. Resuscitation. 2004;61(2):209-19.

35. Bell JD. In vogue: ketamine for Neuroprotection in acute neurologic injury. Anesth Analg. 2017;124(4):1237-43. https://doi.org/10.1213/ANE.0000000000001856.

36. Kuklin $\mathrm{V}$. Survival rate in patients after sudden cardiac arrest at the University Hospital of Northern Norway treated with or without opioids: a retrospective evaluation. Saudi Journal of Anaesthesia. 2013 ;Volume 7.(3) p. 310-314.

37. Elmer J, Lynch MJ, Kristan J, Morgan P, Gerstel SJ, Callaway CW, et al. Pittsburgh post-cardiac arrest service. Recreational drug overdose-related cardiac arrests: break on through to the other side. Resuscitation. 2015;89: 177-81. https://doi.org/10.1016/j.resuscitation.2015.01.028 Epub 2015 Feb 4.

38. Wiberg S, Kjaergaard J, Kjærgaard B, Møller B, Nørnberg B, Sørensen AM, et al. The biomarkers neuron-specific enolase and S100b measured the day following admission for severe accidental hypothermia have high predictive values for poor outcome. Resuscitation. 2017;121:49-53. https://doi.org/10. 1016/j.resuscitation.2017.10.006 Epub 2017 Oct 7.

39. Sheleg SV, Lobello JR, Hixon H, Coons SW, Lowry D, Nedzved MK. Stability and autolysis of cortical neurons in post-mortem adult rat brains. Int J Clin Exp Pathol. 2008;1(3):291-9.

\section{Publisher's Note}

Springer Nature remains neutral with regard to jurisdictional claims in published maps and institutional affiliations.
Ready to submit your research? Choose BMC and benefit from:

- fast, convenient online submission

- thorough peer review by experienced researchers in your field

- rapid publication on acceptance

- support for research data, including large and complex data types

- gold Open Access which fosters wider collaboration and increased citations

- maximum visibility for your research: over $100 \mathrm{M}$ website views per year

At $\mathrm{BMC}$, research is always in progress.

Learn more biomedcentral.com/submissions 